\title{
HUMANISM IN TIMES OF PANDEMIC: ONLINE CLINICAL SIMULATION FOR THE DEVELOPMENT OF ETHICAL COMPETENCIES
}

\author{
Cordero-Díaz MA* and González-Amarante MP
}

\author{
Tecnologico de Monterrey, Escuela de Medicina y Ciencias de la Salud, Mexico
}

\begin{abstract}
The SARS-COV2 health contingency and the cessation of face-to-face activities has motivated multiple educational innovations for distance teaching. Medical schools are particularly defied because of the need for clinical training, however simulation offers opportunities to achieve continuity. A clinical simulation exercise was redesigned and transformed to an online synchronic simulation via Zoom. The participating groups of medical students $(n=53)$ were in the Bioethics and Clinical Bioethics courses, adjunct to their Pediatrics and Obstetrics and Gynecology (ObGyn) clerkships in June 2020. Two simulated clinical cases were performed via Zoom, followed by a debriefing session. Later, an online survey was applied to the participants to know their perception and experience with this new version, considering they had experienced the original face-toface simulation on the alternate clerkship the prior trimester. A mixed method approach was used to analyze the responses. The results showed that the virtual format was very effective, $72 \%$ considered it very similar to the original version. The exercise revealed high emotional commitment, allowing students to develop their socio-emotional skills. Student reactions were categorized and coded as emotions triggered by a) their performance as professionals, b) those related directly to the patient's emotions and situation, which showed significant gender differences, and c) students' anxiety related to the academic exercise itself, the least found. The fact that the clinical component was restructured due to the remote format may have helped in focusing on the preponderance of emotional, communication and relational aspects of the patient-doctor relationship. Also, most students identified the exercise was meaningful in approaching bioethics contents, including end-of-life decisions in patient care, and informed consent. In conclusion, the online clinical simulation activity proved effective in integrating professionalism outcomes that encompass ethical knowledge, skills and attitudes that prepare medical students for their professional role, along with the debriefing reinforcing insightful learning integration.
\end{abstract}

Keywords: educational innovation, higher education, clinical simulation, humanism, ethics

\section{Introduction}

Aside the sanitary crisis, the COVID-19 pandemic has defied education systems all over the world. The abrupt cessation of the presential format forced schools to adapt in order to preserve the continuity and quality through online education. Medical schools in particular faced a greater challenge since they ought to train their students in a series of skills that require a hands-on approach. The pandemic catalyzed opportunities to supply alternative educational interventions by conditioning social distance and limiting physical interaction which forced academic programs and teachers to 
adapt. During March 2020, the School of Medicine at the Tecnológico de Monterrey quickly switched to a fully remote virtual program which required a huge effort. The Bioethics and Clinical Bioethics courses offered during the clinical clerkship phase, regularly included a clinical simulation exercise at the simulation center that emphasized ethical competencies and contents which was already perceived as an innovative practice. This article describes the experience of redesigning the face-to-face clinical simulation exercise to a virtual synchronic simulation via Zoom, during the March-June quarter. Further, it presents the results of an online survey that was applied to participant students in order to prove its perceived efficacy and to gain insight on other aspects of this educational intervention.

\section{Literature Review}

The advent of new technologies for the development of clinical competencies has opened another window for the teaching and evaluation of competencies of professionalism and ethics in medicine. In recent years, the international medical education communities have been concerned with how professionalism should be taught to medical students.

Different pedagogies and methodologies have claimed to develop ethical outcomes, although not considering virtual learning specifically. The line that ethics and professionalism teaching has followed recently parts from the recognition of the nature of the clinical environments and the importance of addressing the hidden curriculum (Stern, 2003, Whitcomb, 2005). In accordance, the traditional lecture format falls short to cover the ethical profile expected from the medical professional.

A review of the literature shows that the main strategies to support the development of professionalism in medical students include curriculum design, teaching and learning methods and role modeling; tangentially, assessment methods and even student selection have been proposed to fulfill the expected profile of medical graduates (Passi et al. 2010). Among the teaching and learning methods, narrative teaching, which is considered a variant of appreciative inquiry, has resulted very effective in prompting reflexive processes for this purpose (Quaintance et al. 2010). These personal reflections should ideally be guided by faculty, which again stresses the importance of the role modeling aspect (Heidari et al. 2013). Similarly, the use of problem-based learning and small group discussion have also shown to be fruitful (Neve and Morris, 2017).

In parallel, simulation, as a teaching and learning tool, has been incrementally used in the last 2 or 3 decades in medical education. Generically, simulation refers to an artificial enactment of a real world scenario to achieve educational purposes through experiential learning, and in medical education it helps replicate clinical scenarios as an alternative to real patients (Al-Elq, 2010). However, as a method, it has been mostly linked to developing concrete clinical skills in deliberate practice for procuring patient safety (Motola et al. 2013). The use of simulation has been minimally reported as a tool for the development of professionalism, nevertheless it has successfully been used to promote the competencies of medical expert, communicator and collaborator which may fall within the scope (Aggarwal, et al. 2010).

Other authors have proposed the use of simulators to evaluate the ethical decision-making of physicians in clinical training (Gabe 2004, Gisondi and Smith 2004, Ziv et al. 2003). Among those 
studies reporting the use of simulation for professionalism in medical education, the majority are used as tools for evaluating programs (Wali et al. 2016).

The shortage of studies reporting simulation-based teaching and learning for the development of ethics and professionalism outcomes has impeded standardized methods and terminology needed for replication as well as supportive evidence to encourage its use (Wali et al. 2016). In spite of this lack of hard evidence, a bibliographic review that analyzed ethics teaching through simulation, recommends simulation as an advisable tool to incorporate when resources are available (Calleja et al. 2020).

Another aspect that has been vaguely explored and became an interest in the present study is the role of emotions in simulation. Real life scenarios, which may be prompted with simulation, trigger emotional involvement in learners (Schuwirth, 2013). Emotions have been recognized to have a valuable and generative role in health professional ethics education (Rees et al. 2013, Gillam et al. 2014, Guillemin and Gillam, 2015).

Further in the realm of simulation as a generic tool for teaching and learning, different techniques could be invoked to produce the scenarios and processes needed, ranging from actors, mannequins, robots, and other technologies, with different degrees of fidelity and synchronicity. This aspect implied the most preponderant change in the redesigning of the learning experience. Determining the appropriate resources and tools according to the purpose of the exercise is another aspect worth exploring finally, the other factor that is highly contingent for this method relies the design of the cases and cues to prompt the circumstances needed for the learning opportunities to emerge.

In consideration of these educational resources, the present study aims to describe the experience of translating a face-to-face clinical simulation exercise to a synchronous virtual clinical simulation with debriefing, and to assess the perceived efficacy in developing medical student's ethical competencies.

\section{Methods}

The study used mixed methods. It consisted of a post intervention survey that was applied to the complete group of students enrolled in the Bioethics courses. The multiple choice items presented with a likert scale were quantitively analyzed, while the open ended question were qualitatively interpreted.

The redesigning of the simulation exercise implicated various considerations. In order to translate the exercise to enable remote learning, the resources previously used that included a high fidelity robot as the standardized patient and 2 actors that acted as the family relative and nurse in the simulation center were replaced by only one actor that played the patient's relative.

The simulation was now to occur virtually and synchronically using the zoom platform, which was justified as a telemedicine type of interaction. The doctor (student) had to deliver the news about the patient's status and discuss next steps in the patient's treatment. The clinical cases used remained the same, however, in the new version the students were given the full case ahead as opposed to acknowledging its evolution during the simulation. 
The students were appointed in smaller teams of 3 members, as opposed to 4 or 5 , to ensure everyone's participation and instructed to cover the roles of interviewer, observer and documenter. Besides the full description of the case and the general instructions, a worksheet was designed to register a collaborative exercise during and after the simulation. The instructional design guided their reflection with some questions using a particular ethical analysis framework described in the British Medical Association "Ethics toolkit for medical students" (2020). This toolkit gives medical students an introduction to common ethical problems and an ethical dilemma analysis framework, a step by step methodology to analyze and resolve ethical problems, developed by the British Medical Association's ethics department.

The actual intervention was carried out in June 2020. Before the simulation session, students were asked by their course instructors to read bibliographic material issuing main themes of the case and to read and consent to the "Fiction and confidentiality agreement for the simulation session" through an internet link in which they accept not to disclose the case to their classmates and get briefed about the importance of affronting the simulated case as though it were real.

The students were randomly appointed in teams and scheduled to enter the zoom session at a particular time. On the day of the simulation, students were managed with break out rooms in the Zoom platform were they received instructions and had time to read the case and get prepared (10 minutes), then met and talked with standardized patient(10 minutes) and finally had a debriefing session (15 minutes). For each team, the exercise took about 35 minutes to elapse.

Debriefing was done with the Plus/Delta model (Eppich et al. 2015), a common learner selfassessment model of debriefing, in which the observer teacher during the simulation became the facilitator of the debriefing process that prompted 4 main questions:

1. What feelings did you experience during the simulation or at present moment regarding the exercise?

2. If you were to reapproach the same scenario, what would you do the same? (assertion of positive performance)

3. If you were to reapproach the same scenario, what would you do differently? (identification of opportunities for a better performance)

4. What new insights and learnings can you transfer to your day-to-day clinical activities?

Finishing the debriefing, the students were asked to answer the 22-item survey. Among the objectives pursued with the instrument were : a) collecting the student's opinion on the design of the virtual activity in contrast to the face-to-face format simulation that they had already experienced in the previous quarter b) Identifying their perceived learnings in the ethical and professionalism scope, and 3)exploring the role of emotions in their experience and performance. Overall, this constituted a way to address the efficacy of the exercise as a tool for ethical and professionalism outcomes development.

\section{Results}

A total of 53 students answered the survey and expressly consented that their answers could be used for the integration of this educational research. The sample consisted of 34 ObGyn and 19 Pediatric students, 24 men and 29 women. The multiple choice and Likert-scale items were processed with 
descriptive statistics, while the open-ended questions were manually coded to detect patterns and main themes.

Regarding the role that they played during the simulation, 19\% $(\mathrm{n}=10)$ of the students identified themselves as documenters and $15 \%(\mathrm{n}=8)$ as observers, while $66 \%(\mathrm{n}=35)$ affirmed having had the role of interviewer or having carried out more than one role in common agreement with their team.

All the pediatric students and $79 \%$ of the ObGyn students participated by speaking at some point during the interview with the family member.

Regarding technical and instructional difficulties, $66 \%$ of the students stated that they had not had any problems, $21 \%$ indicated a poor understanding of the instructions or expectations, and only $13 \%$ reported having had some kind of internet-related failure.

The main purpose of the survey was originally to assess the perception of the students on the new exercise, given that they had participated on the face-to-face scenario the previous quarter. When contrasting the virtual experience with the previous one, $72 \%$ affirm that there was no difference in what they felt or experienced. 21\% marked "neither agree nor disagree" and only $7 \%(\mathrm{n}=4)$ considered any degree of disagreement. It is important to recognize that among the things that the vast majority of students (87\%) appreciate about the classroom format is the opportunity to put their clinical skills to the test.

The fact of already having the diagnosis at the time of the interview (as opposed to discovering it by themselves) was perceived as positive in $51 \%(\mathrm{n}=27)$, although $49 \%(\mathrm{n}=26)$ felt indifferent or in disagreement. The fact that half of the students would rather have full interaction regarding the clinical case is only a matter of opinion, not necessarily a sign of efficacy in terms of the purpose of the exercise.

The next objective was to understand which themes and learnings were elicited through the case. The contents addressed during the exercise referred to by the pediatric students were: a) Communication of bad news b) Compassion, empathy and humanism c) Patient education d) Medical-clinical topic of the case e) end of life care, $f$ ) informed consent and g) legal aspects.

For the ObGyn students, the two most prevalent ones coincide, followed by c) informed consent d) legal aspects e) medical-clinical issue of the case f) implications about a human incubator g) patient education h) end-of-life care and i) organ donation.

Table 1 interprets the nature of these themes based on professional competencies. We deductively attributed the learnings to the different categories that comprise the outcome approach, which includes knowledge learning, skills or abilities, and attitudes and values. 
Table 1: Correlation of professional competencies with the themes addressed in the case.

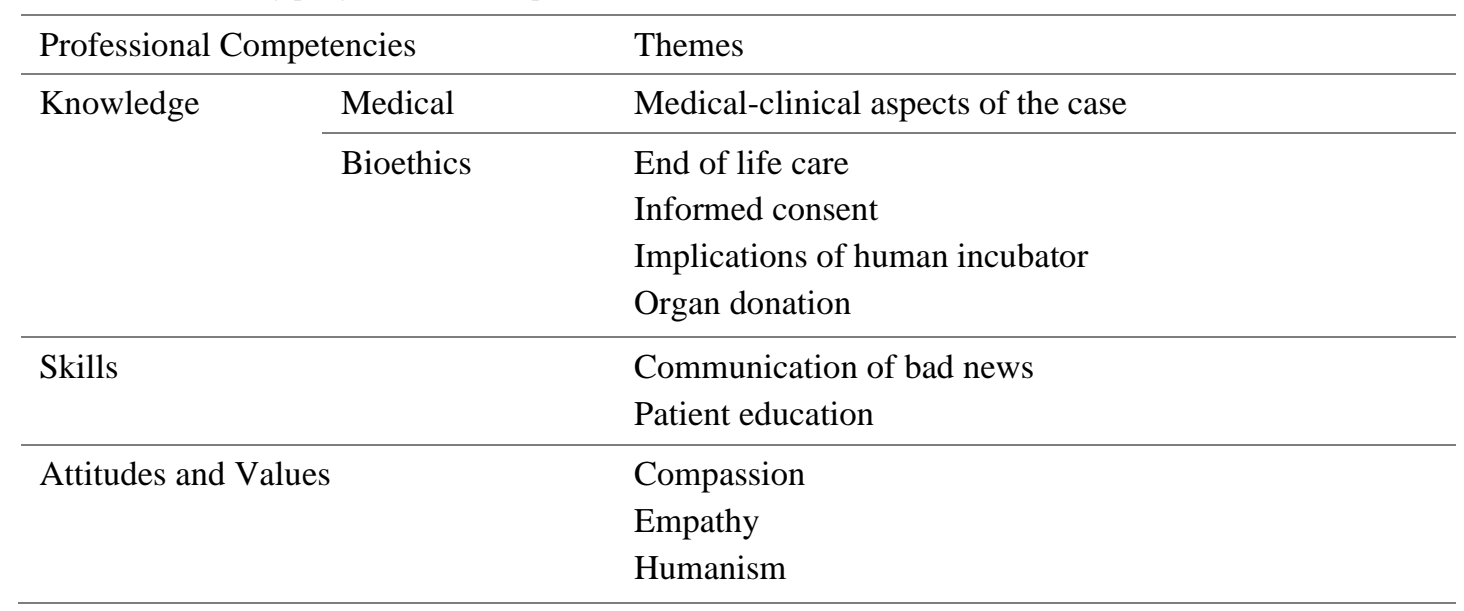

Regarding this debriefing process, in the related items of the survey, most of the students strongly favor that it is a method that serves for the integration of learning, self-discovery and the generation of insights. However, the vast majority claim to have felt fearful about facing their performance during the simulation and show preference for the alternative of having received specific feedback as in what they did "good or bad". This may be also a sign that they feel insecure about their performance and that they may benefit from having more opportunities to practice in order to gain confidence. This indirectly reinforces the importance of simulation in medical education, as a tool to have students develop competencies before they confront real clinical scenarios.

Finally, the exploration of the emotions that the students experienced proved to be very insightful. With regards to the affirmations that were tested using a Likert Scale (Table 2), the most prominent emotions that were present in most of the students were: a) Discomfort at having to say or witnessing bad news and b)Panic or paralysis because of not knowing what to say o how to act. Followed by these, more than half of the students agreed on feeling c) Anxiety about their performance during the simulation d) Sadness when imagining what the person receiving the news must feel and e) Fear that these conditions/illnesses could happen to them or a loved one.

Table 2: Most prevalent emotions. Represents the number of students who chose the answer "strongly agree" or "somewhat agree" according to the Likert scale.

\begin{tabular}{llc}
\hline Emotion instances & $\mathrm{N}$ & $\%$ \\
\hline Discomfort at having to say / witness bad news. & 40 & 75 \\
\hline Panic or paralysis of not knowing what to say or how to act. & 39 & 74 \\
\hline Anxiety about my performance during the simulation. & 32 & 60 \\
\hline Sadness when imagining what the person receiving the news must feel & 31 & 59 \\
\hline Fear that these conditions/illnesses could happen to me or a loved one. & 29 & 55 \\
\hline
\end{tabular}


On the other side, the less prevalent emotions as proved to have registered any degree of disagreement in the Likert Scale items in more than half of the students were a) Disappointment at not having remembered the knowledge requires to tackle the case and b) Pain when thinking about the life of the person who is in critical condition facing death, as shown on Table 3.

Table 3: Less prevalent emotions. Represents the number of students who chose the answer "strongly disagree" or "somewhat disagree" according to the Likert scale.

\begin{tabular}{lll}
\hline Emotion instances & $\mathrm{N}$ & $\%$ \\
\hline Disappointment at not having remembered the knowledge required to tackle the case. & 32 & 60 \\
\hline $\begin{array}{l}\text { Pain when thinking about the life of the person who is in critical condition facing } \\
\text { death. }\end{array}$ & 27 & 51 \\
\hline
\end{tabular}

Aside the multiple choice questions, the qualitative analysis of the responses to the open questions about emotions yielded 3 main categories (Table 4). It is important to note that the open questions were asked prior to the multiple choice items in order not to produce bias with the proposed statements.

The most prevalent category of emotions was related to their performance. Students referred feeling insecurity, stress, confusion, uncertainty, nerves, pressure and anxiety in relation to their concern to do a good job as a professional, aware of the quality and expectations of their role.

The Second category which was present in 15 students, encompassed emotions that arise from the transfer of the painful situation of the "other" (patient or relative) including mentions of sadness, empathy and compassion. Interestingly, among these group only $2 / 15$ were male.

Finally, the third category registered minimal prevalence. Emotions of this third type were related or conditioned by circumstances of the exercise itself, depicting confusion, helplessness and frustration. Table 4 also shows illustrative quotes to represent the nature of the excerpts coded under each category.

Table 4: Categories and quotes of the emotions elicited by the exercise.

\begin{tabular}{lll}
\hline Category & Quotes & Associated emotions \\
\hline $\begin{array}{l}\text { Emotions about } \\
\text { profesional } \\
\text { performance }\end{array}$ & $\begin{array}{l}\text { "Nerves, I wanted to convey to the relative } \\
\text { of the patient the seriousness of the } \\
\text { situation, explain as fully as possible in } \\
\text { words that she understood, make sure there } \\
\text { were no doubts and at the same time show } \\
\text { empathy" }\end{array}$ & $\begin{array}{l}\text { Insecurity, stress, confusion, } \\
\text { uncertainty, nerves, pressure, } \\
\text { anxiety. }\end{array}$ \\
\hline $\begin{array}{l}\text { Emotions related to the } \\
\text { other's pain/suffering }\end{array}$ & $\begin{array}{l}\text { "Compassion for the family member and } \\
\text { the bad news I had to give him, impotence } \\
\text { of not being able to do something else to } \\
\text { help" }\end{array}$ & Sadness, empathy, compassion. \\
\hline
\end{tabular}




\begin{tabular}{lll}
\hline $\begin{array}{l}\text { Emotions prompted by } \\
\text { the exercise itself, or }\end{array}$ & $\begin{array}{l}\text { "A bit of confusion because we were not } \\
\text { good at the case, details were lacking." }\end{array}$ & $\begin{array}{l}\text { Confusion, helplessness, } \\
\text { frustration. }\end{array}$ \\
$\begin{array}{ll}\text { the virtual format. } \\
\text { the interviewer" } \\
\text { "Impotence that something so important } \\
\text { had to be by video call" }\end{array}$ & \\
\hline
\end{tabular}

\section{Discussion}

The process of redesigning a face-to-face exercise simulation became an opportunity to assess its efficacy in terms of the student's perception, but also highlighted interesting aspects about their experience and learning. What may have been only an evaluation of a redesigned virtual clinical simulation became an opportunity to deepen the insights about this educational intervention as a whole.

The virtual format showed to be very effective and perceived highly similar to its face-to-face application. The main difference that arose was the lesser involvement into clinical skills due to the fact that there was not a physical interaction with the patient that requires procedures, and that the outcome of the clinical case was posed from the beginning instead of developed and discovered during the exercise.

Interestingly, the lesser involvement into the clinical skills enabled a keener focus on the relational, emotional, ethical and professionalism aspects within the doctor-patient relationship, as well as the opportunity to concentrate on the reasoning and knowledge of the bioethical academic content of the course.

The high emotional involvement that the students present shows that they are being challenged in the relational aspect and in their social-emotional skills. Students conceive a high-performance standard with respect to their professional role, evident by the prevalence of emotions related to this topic. This aspect may be further developed by more interactive opportunities and exercises to prepare students with the necessary skills for them to feel more prepared when they encounter real life scenarios in which they are expected to perform in such responsibilities.

Regarding the emotional experience of students, which showed to be very prominent, the fact that women were more prone to admitting emotions related to the patient is something worth exploring further, as may be in relation to the ethics of caring (Branch, 2000). This aspect highlights possible gender attritions related to expected forms of experimenting and showing emotions that could be addressed in terms of the professional ethos and role.

Regarding the 3 proposed categories of emotions and their prevalence, tension may arise if students are carried away regarding their concern for their professional performance and distracting their awareness and connection to the patient. Further reflective exercises could invoke the hidden curriculum to understand how their motivation to make a good performance (including causing a good impression in front of faculty) could hinder the best interest of the patient.

Overall, the relevance of the emotional involvement found could mean that the simulated exercises are very effective in representing the conditions of a real scenario. Therefore the exercise represents 
an opportunity to develop the skills required in the complexity of dealing with interpersonal interactions, including communication, empathy and listening in integration with technical-medical skills.

This preponderance of the role of emotions supports the importance of implementing a pedagogical framework to productively incorporate the role of emotions in health professional ethics teaching and promoting ethical mindfulness (Gillam et al. 2014, Guillemin and Gillam, 2015).

Similarly, it may be implied that the continued application of these strategies could help to lower the performance anxiety as long as the students gain competence and self-assertion.

The debriefing process may play as a reinforcer for the integration of learning and self-awareness, but its real preponderance can further be studied to understand how and to what extent does it impact.

Finally, we asserted that the full exercise represents a very complete educational profile which combines problem based learning regarding the clinical case (Neve and Morris, 2017) reflective inquiries (Quaintance et al. 2010) and small group discussion (Neve and Morris, 2017) particularly achieved with the debriefing phase. Furthermore, the written exercise they are asked to fulfill and future feedback regarding the session may provoke insights regarding the hidden curriculum (Stern 2003, Whitcomb, 2005).

Further research recommendations include designing an instrument to evaluate the intervention by the participants and seek opportunities for optimizing it, as well as designing a rubric to assess the students' performance during the simulation exercise using a specific competency based framework.

\section{Conclusion}

In general, the virtual simulation exercise proved to be very effective in contrast with the original face-to-face version, as registered by the post intervention survey.

Furthermore, the exercise was successful in integrating outcomes in the range of knowledge, skills, attitudes and values that prepare students for their professional role. This finding supports the use of clinical simulation as a mean to develop the ethics and professionalism curriculum, and further by proving that it can be done remotely with low cost resources.

The centrality of emotions discovered led to the proposal of three categories that map the feelings that students experienced in order of prevalence: feeling related to the student's professional performance, feelings related to the patient and scarcely those related to the exercise itself and the virtual format. The contribution of these categories may help raise awareness and self-consciousness regarding the role of emotions, especially when it may be a hindered issue in the medical culture through the hidden curriculum. The claim for empathy development in medical education can also be addressed by exploring how self-centered emotions (even if headed for good professional performance) may influence an human and compassionate connection with patients.

Continuous evaluation and research of these academic interventions are key to assert and optimize best practices. In doing so, qualitative analysis is a powerful tool to discover new insights. Other iterations regarding the clinical cases, the debriefing process and even the guided reflection they took 
for homework can be done in order to optimize this learning experience. Another interesting thing to explore in the future regarding the emotional compromise that students showed is the impact of the actor's performance as the standardized patient.

This method could be considered for addressing other aspects of professionalism and ethics in health professions education based on specially designed scenarios to approach them.

\section{Acknowledgments}

The authors would like to acknowledge all the students and teachers that participated in the simulation. And the financial support of Writing Lab, TecLabs, Tecnologico de Monterrey, Mexico, in the production of this work.

\section{References}

Aggarwal, R., Mytton, O. T., Derbrew, M., Hananel, D., Heydenburg, M., Issenberg, B., MacAulay, C., Mancini, M. E., Morimoto, T., Soper, N., Ziv, A., \& Reznick, R. (2010). Training and simulation for patient safety. Quality \& safety in health care, 19 Suppl 2, i34-i43. Retrieved from URL https://doi.org/10.1136/qshc.2009.038562

Al-Elq, A. H. (2010). Simulation-based medical teaching and learning. Journal of family \& community medicine, 17(1), 35-40. Retrieved from URL https://doi.org/10.4103/1319-1683.68787

Birden, H., Glass, N., Wilson, I., Harrison, M., Usherwood, T. \& Nass, D. (2013). Teaching professionalism in medical education: A Best Evidence Medical Education (BEME) systematic review. BEME Guide No. 25. Med Teach, 35(7), e1252-66. doi: 10.3109/0142159X.2013.789132

Branch, W. T. (2000). The ethics of caring and medical education. Academic medicine : journal of the Association of American Medical Colleges, 75(2), 127-132. https://doi.org/10.1097/00001888200002000-00006

British Medical Association (2020). British Medical Association guidance: Ethics toolkit for medical students. "Key principles of ethics for medical students". British Medical Association BMA, 2020. Retrieved from URL https://www.bma.org.uk/advice-and-support/ethics/medical-students/ethicstoolkit-for-medical-students/key-principles-of-ethics-for-medical-students

British Medical Association (2020). British Medical Association guidance: Ethics toolkit for medical students. "Approaching a medical dilemma as a medical student". British Medical Association, 2020. Retrieved from URL https://www.bma.org.uk/advice-and-support/ethics/medical-students/ethicstoolkit-for-medical-students/approaching-a-medical-dilemma

Calleja, J.L., Sánchez, A.S., Soto, P.R. (2020). Is clinical simulation an effective learning tool in teaching clinical ethics? Medwave 20(2). doi: 10.5867/medwave.2020.01.7824

Eppich, W.J., Hunt, E.A., Duval-Arnould, J.M., Siddall, V.J., Cheng, A. (2015). Structuring feedback and debriefing to achieve mastery learning goals. Academic Medicine, 90(11):1501-8.

Gabe, D. (2004). The future vision of simulation in health care. Qual Saf Health Care, 13:12-10.

Gillam, L., Delany, C., Guillemin, M., \& Warmington, S. (2014). The role of emotions in health professional ethics teaching. Journal of medical ethics, 40(5), 331-335. Retrieved from URL https://doi.org/10.1136/medethics-2012-101278

Guillemin, M., \& Gillam, L. (2015). Emotions, narratives, and ethical mindfulness. Academic medicine, 90(6), 726-731. Retrieved from URL https://doi.org/10.1097/ACM.0000000000000709

Gisondi, M. and Smith, R. (2004). Assessment of Resident Professionalism Using High-fidelity Simulation of Ethical Dilemmas. Acad Emerg Med, 11(9): 931-7. 
Heidari, A., Adeli, S. H., Taziki, S. A., Akbari, V., Ghadir, M. R., Moosavi-Movahhed, S. M., Ahangari, R., Sadeghi-Moghaddam, P., Mirzaee, M. R., \& Damanpak-Moghaddam, V. (2013). Teaching medical ethics: problem-based learning or small group discussion? Journal of medical ethics and history of medicine, 6,1 .

Motola, I., Devine, L. A., Chung, H. S., Sullivan, J. E., \& Issenberg, S. B. (2013). Simulation in healthcare education: a best evidence practical guide. AMEE Guide No. 82. Medical teacher, 35(10), e1511-e1530. Retrieved from URL https://doi.org/10.3109/0142159X.2013.818632

Neve, H., Morris, R. (2017). Twelve tips for promoting professionalism through reflective small group learning. MedEdPublish, 6.

Passi, V., Doug, M., Peile, E., Thistlethwaite, J., Johnson, N. (2010). Developing medical professionalism in future doctors: a systematic review. International Journal of Medical Education, 1, 19-29. Retrieved from URL http://doi.org/10.5116/ijme.4bda.ca2a

Quaintance, J. L., Arnold, L., \& Thompson, G. S. (2010). What students learn about professionalism from faculty stories: an "appreciative inquiry" approach. Academic, 85(1), 118-123. Retrieved from URL https://doi.org/10.1097/ACM.0b013e3181c42acd

Rees, C. E., Monrouxe, L. V., \& McDonald, L. A. (2013). Narrative, emotion and action: analyzing 'most memorable' professionalism dilemmas. Medical education, 47(1), 80-96. Retrieved from URL https://doi.org/10.1111/j.1365-2923.2012.04302.x

Schuwirth L. (2013). 'Emotions in learning' is more than merely 'learning of emotions'. Medical education, 47(1), 14-15. Retrieved from URL https://doi.org/10.1111/medu.12078

Stern, D. (2003). Can Professionalism Be Taught? AMA Journal of Ethics, 5:12

Wali, E., Pinto, J. M., Cappaert, M., Lambrix, M., Blood, A. D., Blair, E. A., \& Small, S. D. (2016). Teaching professionalism in graduate medical education: What is the role of simulation? Surgery, 160(3), $\quad 552-564 . \quad$ Retrieved $\quad$ from URL https://doi.org/10.1016/j.surg.2016.03.026

Whitcomb, M. (2005). Medical Professionalism: Can It be Taught? Academic Medicine, 80:10, 883884

Ziv, A., Wolpe, P., Small, S., y Glick, S. (2003). Simulation-Based Medical Education: An Ethical Imperative. Academic Medicine, 78:8, 783-8 